\title{
Kant e a Concepção Contemporânea de Direitos Humanos: Conquistas e Desafios à Teoria Geral dos Direitos Uumanos
}

\author{
Jefferson Luiz de França \\ Mestrando em Direitos Humanos pela Universidade Fede- \\ ral de Pernambuco. Especialista em Filosofia pela Univer- \\ sidade Estácio de Sá. Bacharel em Direito pela Faculdade \\ Integrada de Pernambuco. Analista Jurídico do Ministério \\ Público de Pernambuco.jl_franca@yahoo.com.br
}

\begin{abstract}
Resumo
0 presente artigo relaciona o conceito de dignidade humana em Kant com o desenvolvimento e consolidação da concepção contemporânea de direitos humanos internacionalmente reconhecidos. Em seguida, dá-se destaque ao atual debate enfrentado no âmbito da teoria geral dos direitos humanos entre universalistas e relativistas. Por fim, a tese proposta é de que, superando essa tradicional dicotomia que enxerga o fenômeno por lentes isoladas, a compatibilidade entre os princípios universais postulados pela modernidade e as perspectivas relativistas fruto das reivindicações do pensamento pós-moderno podem ocorrer no seio de uma universalidade relativa, tendo na ideia de dignidade humana seu elemento consensual.
\end{abstract}

Palavras-chave: Kant. Dignidade. Universalidade. Direitos humanos. 


\title{
KANT AND CONTEMPORARY CONCEPTION OF HUMAN RIGHTS: ACHIEVEMENTS AND CHALLENGES TO THE GENERAL THEORY OF HUMAN RIGHTS
}

\begin{abstract}
This paper relates the Kantian concept of human dignity to the development and consolidation of contemporary conception of internationally recognized human rights. Then highlighting the current debate within the general theory of human rights between universalists and relativists. Finally, the thesis proposal that the compatibility between the universal principles postulated by modernity and relativistic perspectives result of the claims of postmodern thought can be given within a relative universality, overcoming this traditional dichotomy which sees the phenomenon by isolated lenses, having the idea of human dignity their consensual element.
\end{abstract}

Keywords: Kant. Dignity. Universily. Human rights.

\section{Sumário}

1 Introdução. 20 Conceito Kantiano de Dignidade e a Internacionalização dos Direitos Humanos. 3 A Perspectiva Universalista de Dignidade e o Fenômeno do Multiculturalismo. 4 Considerações Finais. 5 Referências. 


\section{INTRODUÇÃO}

A denominada concepção contemporânea de direitos humanos teve como marco a introdução da Declaração Universal de 1948, em que se estabelece a proteção universal dos direitos humanos, inspirando inclusive os textos constitucionais de diversos Estados.

Apesar de não ter sido o primeiro documento internacional de direitos humanos, ${ }^{1}$ a Declaração de 1948 lançou as bases legislativas para assegurar a reivindicação de direitos contra as violações perpetradas pelos Estados.

É evidente que tais conquistas não se deram sem controvérsias, pois "nem mesmo os Estados redatores da Declaração se dispuseram seriamente a cumpri-la desde o primeiro momento”, e só em 1993, na Conferência Mundial dos Direitos Humanos, em Viena, foi dado o "passo mais significativo - ainda que não 'definitivo' - no caminho da universalização formal da Declaração de 1948”, ocasião em que se adotou por consenso e, portanto, sem votação e sem reservas, seu documento final: a Declaração e Programa de Ação de Viena. (Alves, 2005, p. 21, 25).

Apesar de todas as dificuldades, esse reconhecimento de direitos de validade universal estabelecida na Declaração de 1948 tem como pano de fundo a ideia de uma dignidade inerente a todos os indivíduos.

O interessante de notar é que essa noção de dignidade humana é amplamente empregada nas mais diversas áreas do conhecimento, ganhando destaque na Filosofia, na política e até mesmo no pensamento comum, quando se trata de justificar ou aplicar princípios,

${ }^{1}$ Basta lembrar que a Declaração dos Direitos do Homem e do Cidadão de 1789, elaborada durante a Revolução Francesa, traz ideais universais, como a liberdade, igualdade e fraternidade humanas. 
assim como para fundamentar certos direitos e deveres morais, tornando-se comum o recurso à Filosofia moral de Kant (Sensen, 2011, p. 1). ${ }^{2}$

Assim, pretende-se situar o conceito kantiano de dignidade humana na construção desta concepção contemporânea dos direitos humanos, sem pôr de lado os novos desafios que emergem no atual debate da teoria geral dos direitos humanos.

\section{O CONCEITO KANTIANO DE DIGNIDADE E A INTERNACIONALIZAÇÃO DOS DIREITOS HUMANOS}

A Filosofia crítica de Kant, filósofo do século 18 e um dos principais expoentes do Iluminismo europeu, representou um significativo marco divisor no pensamento filosófico moderno, constituindo uma verdadeira revolução na investigação filosófica e na possibilidade de fixação dos fundamentos e limites da razão. Essa crítica da própria razão é um convite a mais difícil de suas tarefas: "a do conhecimento de si mesma e da constituição de um tribunal que lhe assegure as pretensões legítimas e, em contrapartida, possa condenar-lhe todas as presunções infundadas" (Kant, 2013, A XI).

Alexandre Morujão (2013, p. XXII-XXIII) afirma que o criticismo kantiano constitui o horizonte filosófico mais próximo da hermenêutica, ligando-se tanto ao movimento hermenêutico quanto, na sequência, ao movimento fenomenológico, tendo em Heidegger uma importante figura, para quem o diálogo com Kant é momento essencial.

\footnotetext{
${ }^{2} \mathrm{O}$ próprio Oliver Sensen adverte que Kant não é o primeiro a teorizar a respeito de uma dignidade humana. Ele afirma que a concepção kantiana de dignidade é "fundamentalmente estoica" e tem como referência os estudos de Cícero e Pico de la Mirandola, todavia coube a Kant refiná-la, emprestando nuances originais.
} 
A mudança no pensar filosófico que se deve a Kant, todavia, não abrange apenas o mundo do conhecimento, mas também o mundo da ação, pois a moralidade no âmbito prático reclama validade universal e objetiva, assim como a ciência no âmbito teórico (Höffe, 2005, p. 183).

Kant dedicou boa parte dos seus estudos à função prática da razão e ao problema da moral, impondo-se quatro problemas fundamentais: (a) determinar o conceito de moralidade; (b) aplicá-lo à situação de entes racionais finitos, o que leva ao imperativo categórico; (c) descobrir a origem da moralidade na autonomia da vontade e (d) provar a efetividade da moralidade com o factum da razão (Höffe, 2005, p. 190).

Ocorre que qualquer defesa ou crítica da ética kantiana deve começar pela Fundamentação da Metafísica dos Costumes, uma obra que tem por propósito a busca e fixação do princípio supremo da moralidade e que contém quase todos os elementos essenciais da moral kantiana (Pascal, 2011, p. 118).

Nela encontra-se a fórmula geral de onde derivam todos os imperativos do dever que, sem tomar em consideração o efeito que dela se espera, tem de determinar uma vontade absolutamente boa e sem restrições. O imperativo categórico é, portanto, um só, que é este: “Age apenas segundo uma máxima tal que possas ao mesmo tempo querer que ela se torne lei universal" (Kant, 2007, BA 52).

O imperativo categórico não impõe nada moralmente neutro. Ao contrário, ele é um dever-ser, uma exortação a agir de determinada maneira, sendo tal a única válida sem nenhuma limitação. Ele diz em que consiste a ação moral, a saber, em máximas universalizáveis (Höffe, 2005, p. 198).

Para H. J. Paton (1971) seria ingênuo pensar que, apenas com a ajuda desse princípio, Kant queira resolver todos os nossos problemas morais, no entanto “o que precisamos é saber aplicar o método 
kantiano. Julgar nossa própria ação pelo mesmo padrão universal que aplicamos para as ações dos outros é uma condição essencial da moralidade" (p. 73).

Ao falar de um imperativo como máximas universalizáveis, Kant afirma que tal dever não pode se propor aos efeitos advindos da ação, a que o filósofo denominou de fins materiais, pois são na sua totalidade apenas relativos e não podem fornecer princípios universais para todos os seres racionais. Dessa forma, um fim objetivo deverá ter um valor universal e, por consequência, ser um fim em si mesmo.

Segundo Kant, não existe na natureza outra coisa cuja existência em si mesma tenha um valor absoluto e que, como um fim em si mesmo, possa ser a base de um possível imperativo categórico: "Ora digo eu - o homem, e, de uma maneira geral, todo o ser racional, existe como um fim em si mesmo, não só como meio para o uso arbitrário desta ou daquela vontade" (Kant, 2007, BA 65).

Isto implica "o reconhecimento dos outros sujeitos morais para as quais a lei deve poder valer” (Abbagnano, 1978, p. 152), resultando numa segunda formulação: a lei universal da humanidade. Tal imperativo prático é, pois, o seguinte: "Age de tal maneira que uses a humanidade, tanto na tua pessoa como na pessoa de qualquer outro, sempre e simultaneamente como fim e nunca simplesmente como meio" (Kant, 2007, BA 66-67).

A aproximação das duas fórmulas origina uma terceira, pois, não devendo ser tratado como instrumento, "o homem não poderia ser um simples objeto da legislação universal imposta pela lei moral; é necessário, pois, que seja ele próprio o seu autor" (Pascal, 2011, p. 132).

Este terceiro princípio prático da autonomia da vontade resulta da "ideia da vontade de todo o ser racional concebida como vontade legisladora universal” (Kant, 2007, BA 70). 
Assim sendo, a essa ideia de autonomia, de autor de sua própria lei, prende-se a ideia da dignidade humana, pois o homem não tem apenas um valor relativo, um preço, mas um valor intrínseco, uma dignidade (Pascal, 2011, p. 133).

Tal dignidade é manifesta na capacidade de o homem alçar a sua máxima à categoria de legislação universal, a qual ele mesmo, simultaneamente, se submete: "A autonomia é, pois, o fundamento da dignidade da natureza humana e de toda a natureza racional” (Kant, 2007, BA 80).

Nesse sentido, afirma Hernandez (2015) que a dignidade humana como a concebemos é inseparável da moralidade e a relação entre ambas é mais bem representada por Kant na sua fórmula da humanidade. E essa conexão entre a dignidade humana e a moralidade proporciona uma resposta eficaz para a discussão do valor humano. Conclui que, "em certo sentido, a dignidade é amplificadora, uma vez que esse valor se torna inseparável da autonomia e dos direitos por ela concedido" (p. 1).

É de notar que tal perspectiva é reflexo de uma ruptura empreendida pelos filósofos modernos que, abandonando a ideia do homem como ser natural, própria da Filosofia clássica, enxerga o homem como um produto de si mesmo, numa concepção mais dinâmica, "baseada no primado da liberdade sobre a inteligência, da prática sobre a teoria, da existência sobre a essência, da história sobre a natureza” (Mondin, 1998, p. 14).

Em Kant, "o homem liberta-se, em virtude da lei moral, do determinismo causal a que está sujeito como ente que vive na natureza e se coloca e se considera positivamente livre, isto é, capaz de iniciar uma nova série causal, independentemente da natureza” (Abbagnano, 1978, p. 142).

Essa formulação implica que o ser humano não é qualquer coisa e, por isso, "não se pode dispor do homem na minha pessoa para mutilá-lo, degradá-lo ou matá-lo” (Tonetto, 2012, p. 272). 
Não por outro motivo, Abbagnano (1998) afirma que a adoção de um princípio de dignidade humana que não concebe o homem como um meio, mas unicamente como um fim em si mesmo, representou uma etapa importante na superação dos grandes regimes totalitários reinantes no século 20:

Como "princípio da dignidade humana" entende-se a exigência enunciada por Kant como segunda fórmula do imperativo categórico: “Age de tal forma que trates a humanidade, tanto na tua pessoa como na pessoa de qualquer outro, sempre também como um fim e nunca unicamente como um meio". Esse imperativo estabelece que todo homem, aliás, todo ser racional, como fim em si mesmo, possui um valor não relativo (como é, p. ex., um preço), mas intrínseco, ou seja, a dignidade.

\section{(...)}

$\mathrm{Na}$ incerteza das valorações morais do mundo contemporâneo, que aumentou com as duas guerras mundiais, pode-se dizer que a exigência da dignidade do ser humano venceu uma prova, revelando-se como pedra de toque para a aceitação dos ideais ou das formas de vida instauradas ou propostas; isso porque as ideologias, os partidos e os regimes que, implícita ou explicitamente, se opuseram a essa tese mostraram-se desastrosas para si e para os outros (Abbagnano, 1998, p. 277).

No mesmo sentido, Fábio Comparato (2003) destaca:

A escravidão acabou sendo universalmente abolida, como instituto jurídico, somente no século XX. Mas a concepção kantiana da dignidade da pessoa como um fim em si leva à condenação de muitas práticas de aviltamento da pessoa à condição de coisa, além da clássica escravidão, tais como o engano de outrem mediante falsas promessas, ou os atentados cometidos contra os bens alheios. Ademais, disse o filósofo, se o fim natural de todos os homens é a realização de sua própria felicidade, não basta agir de modo a não prejudicar ninguém. Isto seria uma máxima meramente negativa. Tratar a humanidade como um fim em si implica o dever de favorecer, tanto quanto possivel, o fim de outrem. Pois, sendo o sujeito um fim em si mesmo, é preciso que os fins de outrem sejam por mim considerados também como meus (p. 22). 
Num estudo sobre os modos pelos quais a soberania estatal se subordina a considerações de natureza ética, Celso Lafer (1995) afirma que o modelo de convivência internacional proposto por Kant, que transcendera o subjetivismo das soberanias e dos interesses, introduzindo a razão abrangente do ponto de vista da humanidade e do indivíduo como fim e não como meio, possibilitou a discussão acerca dos "temas globais" na prática diplomática contemporânea. Para ele,

o desdobramento contemporâneo da visão de Kant são os assim chamados "temas globais", cuja primeira grande afirmação jurídica é o artigo 11 do Pacto da Sociedade das Nações. Este artigo postula a indivisibilidade da paz, explicitando que a guerra ou ameaça de guerra diz respeito não apenas às partes diretamente envolvidas - aos interesses de suas soberanias - mas a toda a sociedade internacional (Lafer, 1995, p. 138).

Examinando, por sua vez, a fundamentação filosófica dos direitos humanos na contemporaneidade, Giovani Lunard (2011) relaciona as máximas da moralidade kantiana com a noção de Direito e de Estado e a influência dessa relação no desenvolvimento de novas teorias jurídicas. Assim,

a atualidade dessa correlação entre moral e direito, e, por conseguinte, com direitos humanos estabelecida por Kant, pode ser comprovada nos seguintes "jusfilósofos” contemporâneos: Rawls, Tugendhat, Habermas, Nino e Alexy. Todos sustentam e realizam "reconstruções" sofisticadas e originais do pensamento kantiano; no entanto, cada um, a sua maneira e em diferentes graus, mantém a mesma fundamentação kantiana filosófica entre "direitos humanos" e "princípios morais" (Lunard, 2011, p. 206-207).

Ainda de acordo com Lunard (2011, p. 207), essa exigência ética dos direitos humanos se expressa, neste século 21, no fenômeno da "constitucionalização do Direito”, localizado em grande parte dos Estados da 
atualidade e em suas relações supranacionais que reivindicam exigências de legitimidade e justificação para além da legalidade de sua normatividade jurídica.

Nesse sentido, a ideia de direitos válidos universal e categoricamente, como fundamento filosófico dos direitos humanos, deve-se especialmente a uma tradição kantiana (Klemme, 2012, p. 187).

Como afirmou Bobbio (2004, p. 9), os direitos humanos são direitos históricos, nascidos em certas circunstâncias, portanto não nascem todos de uma vez, nem de uma vez por todas.

Nesse ponto, Flávia Piovesan (2007, p. 8) esclarece que, considerando a historicidade dos direitos, a chamada concepção contemporânea dos direitos humanos, introduzida pela Declaração Universal de 1948 e reiterada pela Declaração de Direitos Humanos de Viena de 1993, é fruto da internacionalização dos direitos humanos.

Para ela, esse cenário é um movimento recente na História surgido a partir do pós-guerra, como esforço de reconstrução dos direitos humanos. Logo, se a Segunda Guerra significou a ruptura com os direitos humanos, o pós-guerra deveria significar sua reconstrução (Piovesan, 2007, p. 8-9).

Sustentando tal constatação, Hannah Arendt (1998) afirmou que tanto o nazismo alemão quanto o bolchevismo soviético representaram uma ruptura com o paradigma do Direito até então estabelecido, baseados no pressuposto de que os homens tornaram-se supérfluos e inoportunos:

Os homens, na medida em que são mais que simples reações animais e realização de funções, são inteiramente supérfluos para os regimes totalitários. O totalitarismo não procura o domínio despótico dos homens, mas sim um sistema em que os homens sejam supérfluos. O poder total só pode ser conseguido e conservado num mundo de reflexos condicionados, de marionetes sem o mais leve traço de espontaneidade. 
Os Estados totalitários procuram constantemente, embora nunca com pleno sucesso, demonstrar a superfluidade do homem — pela arbitrária escolha de vários grupos para os campos de concentração, pelos constantes expurgos do aparelho do governo, pelas liquidações em massa. O bom senso grita desesperadamente, mas em vão, que as massas são submissas e que todo esse gigantesco aparelho de terror é, portanto, supérfluo; se fossem capazes de dizer a verdade, os governantes totalitários responderiam: o aparelho parece supérfluo unicamente porque serve para tornar os homens supérfluos (Arendt, 1998, p. 508).

Flávia Piovesan (2007, p. 10-11) acrescenta que, nesse esforço de reconstrução dos direitos humanos do pós-guerra, há, de um lado, a emergência do Direito Internacional dos Direitos Humanos, e, de outro, a emergência da nova feição do Direito Constitucional ocidental, aberto a princípios e a valores, com ênfase no valor da dignidade humana, razão pela qual há um reencontro com o pensamento kantiano, com as concepções de moralidade, dignidade, Direito cosmopolita e paz perpétua. E conclui:

Daí a primazia do valor da dignidade humana, como paradigma e referencial ético, verdadeiro superprincípio a orientar o constitucionalismo contemporâneo, nas esferas local, regional e global, doando-lhe especial racionalidade, unidade e sentido (Piovesan, 2007, p. 11-12).

Essa nova concepção fortalece a ideia de que a proteção dos direitos humanos não deve se reduzir ao domínio reservado do Estado, razão pela qual há necessidade de revisar a noção tradicional de soberania absoluta do Estado, transitando-se de uma concepção "hobbesiana” de soberania, centrada no Estado, para uma concepção "kantiana” de soberania, focada na cidadania universal, além de se fomentar a ideia de que o indivíduo, na condição de sujeito de direitos, deve tê-los protegidos na esfera internacional (Piovesan, 2007, p. 8). 
Defendendo a tese de que a total efetivação dos direitos humanos internacionalmente reconhecidos ocorre, entre outros fatores, pelo reconhecimento da personalidade jurídica e da plena capacidade processual do indivíduo como sujeito de direito do Direito Internacional dos Direitos Humanos, Cançado Trindade sustenta que “a base das relações entre o Estado e os seres humanos sob sua jurisdição, assim como das relações entre os Estados em si, não está na soberania estatal, mas na solidariedade humana” (Trindade, 2003, p. 107).

Em estudo recentemente publicado, Peter Häberle (2015, p. 70) defende uma perspectiva da dignidade humana como premissa antropológico-cultural do Estado constitucional, assegurando que a partir dessa ótica emanam as muitas liberdades culturais, como as de religião, de consciência, científica e artística, e essa “cultura da liberdade”, ou "liberdade da cultura”, favorece a democracia pluralista. Para ele:

A democracia pluralista forma uma consequência organizadora da dignidade humana - o que aparece como simples "forma estatal" é uma correspondência mais profunda. $\mathrm{O}$ ser humano dotado de dignidade própria a contar do nascimento cresce graças a processos culturais de socialização em um status de liberdade, que lhe atribui a participação democrática, o status de homo politicus como "natural". Dignidade humana e democracia formam as duas faces da mesma res publica, que dão forma ao Estado constitucional do atual estágio de evolução. A ilustração e o entendimento ocidental da democracia atuam profundamente. A dignidade e o valor próprio da pessoa tiveram de ser concebidos por filósofos antes de se "coagularem” em princípios jurídicos. A democracia teve de ganhar-se lutando bem duramente - partindo da Inglaterra -, até que amadureceu nesse conjunto de procedimentos e instituições múltiplas que hoje a caracteriza. Competência e diversidade, alternativas e oposição, a alternância de maioria e minoria, o desenvolvimento aberto - tudo isso são consequências da dignidade humana como premissa antropológico-cultural do Estado constitucional (Häberle, 2015, p. 70). 
Se, por um lado, a concepção contemporânea dos direitos humanos internacionalmente reconhecidos encontra apoio nas formulações kantianas de moralidade e dignidade humanas, por outro ela faz surgir novos desafios à teoria geral dos direitos humanos.

Como Lindgren Alves esclarece, a modernidade clássica se propunha racional, secular, democrática e universalista até que, na virada do século 19 para o século 20, deu-se um movimento de ruptura que abriu o caminho para o pós-modernismo com Nietzsche e a genealogia da moral, Freud e o estudo do inconsciente, Saussure e as estruturas de linguagem, além de Foucault e os estudos acerca da capilaridade do poder, desmontando o racionalismo iluminista e lançando as bases para a "desconstrução do sujeito" (Alves, 2005, p. 30-31).

A pós-modernidade passa então a exigir não mais uma natureza universal, mas um modelo de especificidade concreta.

\section{A PERSPECTIVA UNIVERSALISTA DE DIGNIDADE E O FENÔMENO DO MULTICULTURALISMO}

A questão, portanto, que se impõe atualmente é como os princípios de validade universal, a exemplo dos formulados pela teoria moral kantiana, se comportam perante o fenômeno do multiculturalismo. Essa é a clivagem travada no pensamento social contemporâneo entre universalistas e relativistas.

Uma das principais críticas que se faz à adoção de princípios éticos universais é que tal abstração põe de lado aspectos da realidade, conduzindo necessariamente a uma nivelação inaceitável do comportamento social, pela aplicação desses princípios e normas. Uma outra sustenta frequentemente que a defesa de uma perspectiva universalista tem subjacente uma posição etnocêntrica (Rocha, 2000, p. 60-61). 
O que se afirma é que não há qualquer semelhança entre os seres humanos que comporte generalizações. Pelo contrário, o que há são múltiplas tradições culturais.

Essa reação contra o universalismo das teorias modernas dos direitos humanos é um dos pilares do comunitarismo, movimento surgido notadamente nos Estados Unidos, que reivindica a Filosofia prática aristotélica e defende $\mathrm{o}$ abandono de princípios universalizantes para fundamentar o comportamento moral, tendo por principais representantes Alasdair MacIntyre, Michael Sandel e Charles Taylor (França, 2015, p. 238).

Para Acílio Rocha, tal "disputa entre comunitaristas e liberais pode ser vista como uma espécie de reedição da grande controvérsia entre as posições kantianas e hegelianas" (2000, p. 63). Ou, nas palavras de Carlos Nino (1988, p. 363), o espectro de Hegel desafia mais uma vez o espírito de Kant.

Há também na América Latina um crescente movimento conhecido como descolonialismo, que busca construir uma frente contra o pensamento hegemônico europeu e norte-americano. ${ }^{3}$

Jack Donnelly (2013) propõe uma saída para esse imbróglio, com base numa ruptura dessa tradicional dicotomia, segundo a qual enxergar o problema da universalidade/relatividade dos direitos humanos por lentes isoladas induz ao erro e engano.

Estabelecendo uma demarcação temporal na discussão, Donnelly afirma que na década de 80 , quando ditadores cruéis recorriam à cultura local para justificar suas atrocidades, a ênfase na universalidade dos direitos humanos parecia não apenas apropriada, mas essencial. Hoje, essa primazia foi posta em xeque a partir da corriqueira política externa

\footnotetext{
${ }^{3}$ Quanto a esse movimento e suas principais reivindicações, cf. Martins, Paulo Henrique. La decolonialidad de América Latina y la heterotopía de una comunidad de destino solidaria. Buenos Aires: Fundación Ciccus, 2012.
} 
norte-americana que "apela regularmente para os valores 'universais' na busca de uma guerra ideológica global que zomba das normas jurídicas internacionais” (Donnelly, 2013, p. 282).

Para este autor, os direitos humanos são universais na medida em que são realizados "universalmente" por todos os seres humanos; em outras palavras, são iguais e inalienáveis. Essa conceituação, porém, não prova que tais direitos existem e por possuírem um nível alto de abstração parecem ter pouca importância prática, ou seja, nada diz sobre a questão central na maioria das discussões contemporâneas sobre a universalidade dos direitos humanos (2013, p. 283).

Por outro lado, o que se tem são “consensos” em que cada cultura, seja ela indígena, americana, europeia, africana ou asiática apoia suas práticas numa concepção política de justiça e, nesse sentido, nenhuma cultura ou doutrina é "por natureza" incompatível com os direitos humanos. A esse fenômeno, Donnelly chamou de "universalidade consensual sobreposta" (2013, p. 291).

Como exemplo, explica, poucas civilizações praticam ou justificam a escravidão humana. Daí porque o relativismo cultural na sua espécie normativa (que defende a ausência de força normativa da Declaração Universal dos Direitos Humanos ante as diferentes tradições culturais) é uma teoria profundamente problemática que oferece uma compreensão deficiente do fenômeno da relatividade dos direitos humanos, pois: (a) reduz o "direito" ao "tradicional” e o "obrigatório" ao "habitual”; (b) o fato de um valor ou prática surgir num determinado lugar não impossibilita de per si sua aplicação noutros lugares, acabando por assumir, desse modo, a impossibilidade da aprendizagem e adaptação humanas; (c) não fornece padrão que sustente qualquer desaprovação quanto às violações aos direitos humanos; (d) fazem pouco caso dos aspectos políticos ou mesmo os confunde com aspectos culturais; (e) desconhece os impactos 
dos Estados, do mercado, da propagação de ideias dos direitos humanos e de outras forças sociais; (f) ignora a contingência cultural, a contestação e a mudança (Donnelly, 2013, p. 293 et seq.).

Reconhecendo os perigos dos argumentos extremistas de ambos os lados (universalistas e relativistas), Donnelly (2013, p. 298) defende a universalidade dos direitos humanos sem a exclusão de práticas não idênticas, a que classificou como "universalidade relativa". ${ }^{4}$

Essa universalidade relativa é perfeitamente compatível com as formulações gerais da Declaração Universal dos Direitos Humanos que assegura, por exemplo, que todos têm direito à vida, à liberdade, à segurança, à educação, à participação política.

Apesar de universalmente realizados por todos os seres humanos, no entanto, tais direitos gozam de formas específicas de efetivação e permitem uma ampla gama de práticas particulares.

Para Donnelly, tais concepções particulares podem até resultar em desvios das normas internacionais de direitos humanos, mas é preciso olhar com certa "simpatia" para tais desvios, pois eles tendem a diminuir na medida em que aumentam os consensos sobrepostos.

Nesse sentido, "a universalidade (relativa) dos direitos humanos internacionalmente reconhecidos não requer, ou mesmo encoraja, uma homogenização global ou o sacrifício de (muitas) práticas locais valorizadas" (Donnelly, 2013, p. 303).

\footnotetext{
${ }^{4}$ Lindgren Alves (2005, p. 34) também sugere uma compatibilização entre o particularismo das diversas culturas e a ideia universal de direitos fundamentais, como: a assimilação generalizada dos direitos individuais aos ensinamentos cristãos sobre a dignidade e a fraternidade humanas; uma interpretação atualizada e a reforma da sharia islâmica; a incorporação dos direitos humanos no dharma da tradição hindu, entre outras.
} 
Essa perspectiva considera tais direitos humanos universalmente realizáveis, na medida em que possibilitam aos seres humanos, individualmente ou em grupos, sentido e valor à existência para que prossigam com suas próprias visões de uma boa vida.

Assim, ambas as perspectivas não se excluem mutuamente, antes exigem uma abordagem mais dialógica, reflexo da crescente sofisticação das relações humanas.

\section{CONSIDERAÇÕES FINAIS}

É inegável que a universalidade jurídica internacional é um grande feito na reconstrução e solidificação dos direitos humanos, tendo na formulação kantiana de dignidade humana um importante marco teórico, e que possibilita a passagem de um Estado hermeticamente soberano para um Estado de soberania colaborativa.

Kant não prescreveu um único modo de vida, antes reclamou o respeito pela humanidade e sua estrutura filosófica moral possibilita um amplo espectro de liberdade para o indivíduo e sociedade, razão pela qual "as diferentes considerações de boa vida são permitidas, desde que a liberdade possa coexistir com a liberdade de todos e não viole os deveres para consigo mesmo" (Sensen, 2011, p. 140).

A compatibilização entre os princípios universais e o universo cultural variado, no entanto, é algo bastante desafiador, especialmente pelo fato de que essa noção de "direitos" é típica do Ocidente, contrapondo-se à noção de "deveres” das culturas não ocidentais.

Por isso, pensar uma universalidade relativa, adotando um universalismo não imperialista associado a um relativismo com critérios mínimos baseados em consensos sobrepostos parece ser uma boa saída para o problema contemporâneo da teoria geral dos direitos humanos. 
Assegurar essa "universalidade consensual sobreposta" - que pode se dar na ideia de uma dignidade humana realizável por todos os indivíduos - pela qual perpassam as mais diferentes matizes culturais, possibilita que, sob um eixo comum, se articule diversas possibilidades de execução e permite a utilização de um mínimo denominador comum e de um parâmetro suficiente de juízo.

Essa é, sem dúvida, uma tarefa que cabe a todos aqueles que desejam construir uma sociedade mais justa e humana.

\section{REFERÊNCIAS}

ABBAGNANO, Nicola. História da filosofia. Tradução Antônio Ramos Rosa e Antônio Borges Coelho. 2. ed. Lisboa: Editorial Presença, 1978. V. VIII. . Dicionário de filosofia. São Paulo: Martins Fontes, 1998.

ALVES, José Augusto Lindgren. Os direitos humanos na pós-modernidade. São Paulo: Perspectiva, 2005.

ARENDT, Hannah. Origens do totalitarismo. Tradução Roberto Raposo. 3. reimp. São Paulo: Companhia das Letras, 1998.

BOBBIO, Norberto. A era dos direitos. Tradução Carlos Nelson Coutinho. Rio de Janeiro: Elsevier, 2004.

COMPARATO, Fábio Konder. A afirmação histórica dos direitos humanos. 3. ed. São Paulo: Saraiva, 2003.

DONNELLY, Jack. The relative univerlality of human rights. Human Rights Quarterly, v. 29, n. 2, p. 281-306, maio 2013.

FRANÇA, Jefferson Luiz. Alguns aspectos sobre o direito natural na Ética a Nicômaco de Aristóteles (EN, V, 10, 1134b18-1135a5). Hypnos, São Paulo, v. 35, p. 231-245, $2^{\circ}$ sem., 2015. 
HÄBERLE, Peter. O fundamentalismo como desafio do Estado Constitucional: considerações a partir da Ciência do Direito e da Cultura. $R D U$, Porto Alegre, v. 11 , n. 62 , p. 58-80, mar./abr. 2015.

HERNANDEZ, Jill Graper. Human value, dignity and the presence of others. HEC FORUM: An Interprofessional Journal on Healthcare Institution's Ethical and Legal Issues., p. 1-15, 2015.

HÖFFE, Otfried. Immanuel Kant. Tradução Christian Viktor Hamm e Valerio Rohden. São Paulo: Martins Fontes, 2005.

KANT, Immanuel. Crítica da razão pura. Tradução Manuela Pinto dos Santos e Alexandre Fradique Morujão. 8. ed. Lisboa: Fundação Calouste Gulbenkian, 2013.

. Fundamentação da metafísica dos costumes. Tradução Paulo Quintela. Lisboa: Edições 70, 2007.

KLEMME, Heiner F. Direito à justificação - dever de justificação: reflexões sobre um modus de fundamentação dos direitos humanos. Trans/Form/Ação, Marília, v. 35, n. 2, p. 187-198, maio/ago. 2012.

LAFER, Celso. A soberania e os direitos humanos. Lua Nova, n. 35, p. 137148, 1995.

LUNARD, Giovani Mendonça. A fundamentação moral dos direitos humanos. Revista Katálysis, Florianópolis, v. 14, n. 2, p. 201-209, jul./dez. 2011.

MARTINS, Paulo Henrique. La decolonialidad de América Latina y la heterotopía de una comunidad de destino solidaria. Buenos Aires: Fundación Ciccus, 2012.

MONDIN, Battista. Definição filosófica da pessoa humana. Tradução Ir. Jacinta Turolo Garcia. São Paulo: Edusc, 1998.

MORUJÃO, Alexandre Fradique. Introdução, notas e tradução. In: KANT. Crítica da razão pura. 8. ed. Lisboa: Fundação Calouste Gulbenkian, 2013. NINO, Carlos Santiago. Liberalismo versus comunitarismo. Revista del Centro de Estudios Constitucionales, n. 1, p. 363-376, 1988. 
PASCAL, Georges. Compreender Kant. Tradução Raimundo Vier. 7. ed. Petrópolis, RJ: Vozes, 2011.

PATON, H. J. The categorical imperative: a study in Kant's moral philosophy. Philadelphia: University of Pennsylvania Press, 1971.

PIOVESAN, Flávia. Direitos humanos e justiça internacional: um estudo comparativo dos sistemas regionais europeu, interamericano e africano. 1. ed. 2. tir. São Paulo: Saraiva, 2007.

ROCHA, Acílio da Silva Estanqueiro. Relativismo cultural versus universalismo ético. Arquipélago, Série Filosofia, n. 7, p. 57-92, 2000.

SENSEN, Oliver. Kant on human dignity. Berlin; Boston: De gruyter, 2011. TONETTO, Milene Consenso. A dignidade da humanidade e os deveres em Kant. Rev. Filos. Aurora, Curitiba, v. 24, n. 34, p. 265-285, jan./jun. 2012.

TRINDADE, Antônio Augusto Cançado. El nuevo reglamento de la Corte Interamericana de Derechos Humanos y su proyección hacia el futuro: la emancipación del ser humano como sujeto del derecho internacional. El futuro de la Corte Interamericana de Derechos Humanos. San José, C.R.: Corte IDH, 2003.

Recebido em: 22/10/2015

Revisões requeridas em: 3/11/2015

Aceito em: 9/11/2015 